\title{
A DIGNIDADE E A AUTONOMIA GARANTIDAS PELO ESTADO HEGELIANO
}

The dignity and autonomy guaranteed by the State Hegelian

\author{
Mariana Secani Lucas Fredes*
}

Resumo: Hegel, filósofo do século XIX, com sua Filosofia que pode ser denominada de "orgânica", expõe conceitos necessários para o entendimento das relações humanas, entre estes estão o conceito da liberdade, de direitos, de autonomia e de dignidade. Em sua obra Filosofia do Direito, a eticidade é a fase final da evolução social, na qual estão contidas as instituições sociais, incluindo o Estado. Este, por sua vez, permite a efetivação da liberdade, visto que isto, para este autor, é o principal objetivo do Estado, e, consequentemente garante a autonomia e a dignidade humanas. Este ensaio pretende elucidar os conceitos de autonomia e de dignidade, juntamente com o de liberdade na Filosofia do Direito de Hegel, remetendo-se ao longo do estudo, a Cícero, a Pico della Mirandola, a Tomás de Aquino, a Pufendorf e a Kant, visando a uma comparação breve, objetivando enfatizar as definições.

Palavras-chaves: Dignidade. Autonomia. Liberdade. Estado.

\begin{abstract}
Hegel, Philosopher of the 19th century, with its Philosophy that can be called "organic", exposes necessary concepts for the understanding of human relations, among these are the concept of freedom, rights, autonomy and dignity. In his work Philosophy of Law, ethics is the final stage of social evolution, in which are contained the social institutions, including the State. This, in turn, allows the realization of freedom, as this, for this author, is the main objective of the State, and consequently ensures the autonomy and human dignity. This essay seeks to elucidate the concepts of autonomy and dignity, together with the concept of freedom in Hegel's Philosophy of Right, and advising throughout the study, to Cicero, Pico della Mirandola, Thomas Aquinas, to Pufendorf and Kant, aiming at a brief comparison, and to emphasize the definitions.
\end{abstract}

Keywords: Dignity. Autonomy. Freedom. State.

\footnotetext{
* Mestranda do Programa de Pós-graduação em filosofia da Universidade Federal de Pelotas (UFPel) Bolsista CAPES. Contato: mari_nihil@hotmail.com
}

\begin{tabular}{|c|c|c|c|c|c|}
\hline intuitio & $\begin{array}{c}\text { ISSN } \\
1983-4012\end{array}$ & Porto Alegre & Vol.7 $-\mathrm{N}^{\mathrm{o}} .2$ & $\begin{array}{c}\text { Novembro } \\
2014\end{array}$ & p. 226-235 \\
\hline
\end{tabular}


Hegel (1770-1831) expõe, em sua obra Filosofia do Direito o desenvolvimento da capacidade social do ser humano, distribuída em um sistema que se define como Direito Abstrato, Moralidade e Eticidade. Nesta estrutura estão inseridas a dignidade e a autonomia humana, que precisam ser expostas juntamente com a liberdade e a razão para que se possa compreender estes conceitos. Nesse sentido a Filosofia de Hegel pode ser comparada com um tecido orgânico, no qual existem ligações que não podem ser desfeitas, pois significaria o rompimento das relações entre os seres humanos. Ou pode-se dizer que na concepção orgânica da Filosofia de Hegel existem relações, e se os conceitos não estão presentes, o sistema como um todo não funciona.

Com isso entende-se a importância de elucidar os conceitos da dignidade e autonomia do ser humano contida no Estado. Para tanto, este estudo tem propósito de esclarecer alguns aspectos relacionados com autonomia, dignidade, liberdade e o Estado utilizando principalmente o pensamento de Hegel, mas utilizando ainda de conceitos de filósofos relacionados ao tema da dignidade. Como primeiro momento desta investigação está o apontamento da concepção de alguns filósofos relacionado ao tema da dignidade, trazendo Cícero, Pico della Mirandola, Tomás de Aquino e Pufendorf para mostrar brevemente suas concepções de dignidade, utilizando ainda Kant para diferenciar e contrapor ao pensamento hegeliano. Sendo esta uma primeira aproximação ao tema, tais perspectivas são imprescindíveis para demonstrar a relevância do tema e a complexidade do mesmo, com objetivo de explicitar os principais conceitos que ela envolve, sem, entretanto, aprofundá-los, o que demanda uma investigação mais acurada, tendo em vista que o tema é abordado, por exemplo, no início de cada constituição que deseje contemplar o ser humano.

A ideia de dignidade vem sendo pensada como valor imanente ao ser humano por filósofos de diversas épocas, desde a Antiguidade, até a Modernidade, continuando ainda até os dias de hoje. Diversos pensadores contribuíram para que o conceito de dignidade tenha evoluído, Cícero (106-43 a.C.) foi um destes pensadores. Sua contribuição foi tomada por filósofos posteriores, como Kant (1724-1804), sendo a base para a formação de suas próprias acepções. No pensamento de Cícero, a dignidade está ligada a uma rejeição ao hedonismo ${ }^{1}$, afirmando que o homem está destinado a não se deixar determinar por seus impulsos e usar de sua razão, reconhecendo o que deve fazer. Assim:

Daqui se pode deduzir não ser o prazer do corpo suficientemente digno da superioridade do homem, devendo ser não só desprezado como ainda rejeitado. [...] Além disso, se é nossa intenção considerar ainda o que sejam, segundo a nossa natureza, a superioridade e a dignidade, então compreenderemos como é vil dissiparnos na luxúria, assim vivendo sem qualquer energia e no meio da maior voluptuosidade, e como é bom viver uma vida de parcimônia e de continência, austera e sóbria. $^{2}$

\footnotetext{
${ }^{1}$ De acordo com Abbagnano (ABBAGNANO, Nicola. Dicionário de Filosofia. 5 ed. São Paulo: Martins Fontes, 2007, p.497): Hedonismo "indica tanto a procura indiscriminada do prazer, quanto a doutrina filosófica que considera o prazer como o único bem possível, portanto como o fundamento de vida moral".

${ }^{2}$ CÍCERO. Dos Deveres (De Officiis). Lisboa, Portugal: Edições 70, p. 53.
}

\begin{tabular}{|c|c|c|c|c|c|}
\hline intuitio & $\begin{array}{c}\text { ISSN } \\
1983-4012\end{array}$ & Porto Alegre & Vol.7- No.2 & $\begin{array}{c}\text { Novembro } \\
2014\end{array}$ & p. 226-235 \\
\hline
\end{tabular}


A dignidade, para Cícero, é racional, sendo resultado de um empenho pessoal de se deixar orientar seja pela razão ou pela fé. O reconhecimento do bem se torna condutor da ação, pois uma vida de falha é falta de conhecimento de discernimento.

A liberdade não necessariamente eleva o homem do animal, mas eles se distinguem por meio dela, assim, o homem ainda é um animal, porém um animal racional: este precisa manter sua racionalidade, pois pode se tornar um mero animal a qualquer momento, tornando-se o pior dos animais. Contudo, é oportuno expor que o que distingue o homem do animal, para Kant, por exemplo, é a sua capacidade de agir conforme máximas, justificá-las e contribuir com leis universais. Nesta mesma perspectiva, Hegel na obra Filosofia do Direito afirma: "apenas os animais têm a sua lei enquanto instinto, mas somente os homens são os que têm essa lei enquanto um hábito"3.

Pico della Mirandola (1463-1494) expõe esta distinção entre o homem e os seres não racionais em seu pensamento. De acordo com Sensen:

Pico considera o lugar do homem no seio da "ordem universal" ou na "cadeia do ser" que se estende de Deus ao menor dos animais, e ele conclui que a dignidade inicial do homem consiste em não ter lugar fixo nesta corrente. Em vez disso, a dignidade do ser humano reside na sua capacidade de escolher o seu próprio lugar nesta cadeia $^{4}$.

Mirandola então presume que o homem possui dignidade inicialmente, devido ao fato de ser homem e não possuir um lugar definido na cadeia dos seres vivos (chain of being), sendo digno por ter a capacidade de escolher seu lugar nesta tal cadeia. Sendo assim, "Pico alega, em suma, que os seres humanos são livres para escolher o seu caminho na vida, e que isso é o que eleva os seres humanos

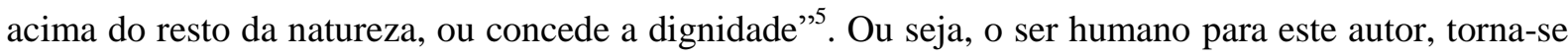
algo mais do que um mero animal que nasce, cresce, se reproduz e morre, sendo livre para conduzir sua vida, possuindo assim a dignidade.

A dignidade possui uma acepção diferente no pensamento cristão, na qual o conceito de dignidade está relacionado à imagem e semelhança de Deus. Sendo assim, ela está contida desde sempre no homem, não podendo adquirir ou perder. Trata-se de um status o qual o homem deve ajustar sua postura, pois é preciso preservar e agir de acordo com esta dignidade. A partir da imagem e semelhança de Deus é imperioso que o homem obedeça aos mandamentos de Deus, e estes não são arbitrários, pois são obra da Sabedoria Divina, isto é, são mandamentos criados para o homem, pois

\footnotetext{
${ }^{3}$ HEGEL, G. W. F. Linhas fundamentais da filosofia do direito, ou, Direito natural e ciência do estado em compêndio. São Leopoldo: Loyola, 2010, § 211, p. 204.

${ }^{4}$ SENSEN, Oliver. Kant on human dignity. Gottingen: Gruyter, 2011, p. 160. Tradução nossa. ("Pico considers the place of man within the "universal order" or the "chain of being" that stretches from God to the lowest animals, and he concludes that the initial dignity of man consists in having no fixed place in that chain. Rather, the dignity of human being lies in their capacity to choose their own place on that chain").

${ }^{5}$ SENSEN, Oliver. Kant on human dignity. Gottingen: Gruyter, 2011, p. 160. Tradução nossa. ("Pico's claim, in short, is that human beings are free to choose their path in life, and that this is what lifts human beings up above the rest of nature, or gives them a dignity").
}

\begin{tabular}{|c|c|l|l|c|c|}
\hline intuitio & $\begin{array}{c}\text { ISSN } \\
1983-4012\end{array}$ & Porto Alegre & Vol.7- $\mathrm{N}^{\mathrm{o} .2}$ & $\begin{array}{c}\text { Novembro } \\
2014\end{array}$ & p. 226-235 \\
\hline
\end{tabular}


Deus, sendo o Bem perfeito, também cria regras e mandamentos perfeitos: segui-las é igualar-se a Deus, assim, o homem corresponde à essência de Deus, e é digno.

Ora, em Tomás de Aquino (1225-1274) a dignidade pode ser atribuída a todos os seres racionais, pois "subsistir na natureza racional é de máxima dignidade", ela pertence a todos os seres que são dotados de razão e que não são movidos por seus impulsos, pois eles são capazes de submeter seus impulsos à razão para fins elevados, ou seja, autodeterminar-se. Ademais, "a dignidade é algo absoluto e pertence à essência" ${ }^{\prime 7}$, isto é, ela é perfeita e existe na essência do ser humano. Ao mesmo tempo a dignidade implica um trabalho, e aquele que não consegue cumpri-lo, perde sua dignidade, diferente da dignidade em Kant e Cícero, a qual não é passível de ser perdida.

Para Pufendorf (1632-1694), a dignidade é exposta como possuindo diferentes graus, e existindo, em cada ser humano, um mínimo de dignidade. Ele considera, então, que a dignidade provém da natureza humana: "Por isso é sua maior honra, que ele tenha obtido uma Alma Imortal, ainda com a Luz do Entendimento, possuindo as Faculdades de juízo e de perseguir as coisas, e com uma admirável Capacidade para Artes e Conhecimento" ${ }^{\text {}}$. Sendo assim entende-se que a dignidade do homem consiste em ter essa alma imortal contendo a luz do entendimento, a faculdade de julgar e de escolher, e ainda, a capacidade para as artes e para o conhecimento. Sendo essas atribuições provindas da dignidade.

Os conceitos de dignidade apresentados até então não faziam parte do âmbito moral. Kant assume alguns conceitos clássicos em seu pensamento, e é a partir dele que a dignidade humana ganha uma base moral. Ele entende a dignidade como existente na capacidade do homem de não se deixar determinar por inclinações, enfatizando a independência do homem, a liberdade, visto que o homem é aquele que se deixa determinar ou não pelos impulsos, por meio do uso em geral da razão, pois, o dever é um querer para a razão.

O homem possui racionalidade, possui liberdade e boa vontade, que o ajuda a participar do reino dos fins e ter sua dignidade. Pois: "No reino dos fins tudo tem ou um preço ou uma dignidade. Quando uma coisa tem um preço, pode-se pôr em vez dela qualquer outra como equivalente; mas quando uma coisa está acima de todo o preço, e portanto não permite equivalente, então tem ela

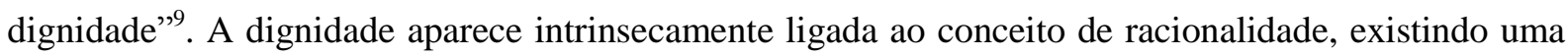
mútua dependência.

\footnotetext{
${ }^{6}$ AQUINO, Santo Tomás de. Suma de Teología. 4.ed. Espanã: Biblioteca de autores cristianos, 2001, p. 327. Tradução nossa. ("subsistir em la naturaleza racional es de la máxima dignidad").

${ }^{7}$ AQUINO, Santo Tomás de. Suma de Teología. 4.ed. Espanã: Biblioteca de autores cristianos, 2001, p. 411. Tradução nossa. ("la dignidad es algo absoluto y pertende a la esencia").

${ }^{8}$ PUFENDORF, Samuel von. Of the law of nature and nations. 1. ed. Oxford: L. Lichfield, 1710, p. 78. Tradução nossa. ("Hence it is his greatest Honour, that he has obtain'd an Immortal Soul, indu'd with the Light of Understanding, whit the Faculties of judging and of chasing things, and with an admirable Capacity for Arts and Knowledge").

${ }^{9}$ KANT, Immanuel. Fundamentação da Metafísica dos Costumes. Lisboa, Portugal: Edições 70, 2009, BA 77. Grifos do autor.
}

\begin{tabular}{|c|c|l|l|c|c|}
\hline intuitio & $\begin{array}{c}\text { ISSN } \\
1983-4012\end{array}$ & Porto Alegre & Vol.7- $\mathrm{N}^{\mathrm{o} .2}$ & $\begin{array}{c}\text { Novembro } \\
2014\end{array}$ & p. 226-235 \\
\hline
\end{tabular}


Na Fundamentação da Metafísica dos Costumes, Kant pretende identificar e justificar o princípio supremo da moralidade. Ele alega que não é possível elaborar um princípio supremo da moralidade e impor ao ser humano que o siga, combatendo a possibilidade de encontrar o fundamento da moralidade fora do homem. A racionalidade é o fundamento desse princípio supremo da moralidade, ou seja, o ser humano, sendo racional, age unicamente pelo padrão do dever. Ao agir moralmente, ele não deixa que os desejos comandem as ações instintivamente: ele utiliza da razão para mediar as ações. A razão é, pois, a responsável pelo princípio supremo, o dever, sendo esta a única capaz de reconhecer esse princípio. Para Kant, a ação tem valor moral quando realizada por dever, pois está de acordo com a razão, estas ações possuem valor moral.

Os princípios morais devem ser buscados, de acordo com esse filósofo, por meio da razão, excluindo a possibilidade de buscá-los por meio de observações ou de estudos de exemplos. Pois os princípios morais se aplicam a todos os seres racionais de forma autônoma, e não apenas em casos específicos, ou por imitação ao se utilizar de exemplos que têm como pré-definido a forma correta de agir, contrariando assim a concepção de princípio moral. Nas palavras de Kant:

E então nada nos pode salvar da completa queda das nossas ideias de dever, para conservarmos na alma o respeito fundado pela lei, a não ser a clara convicção de que, mesmo que nunca tenha havido ações que tivessem jorrado de tais fontes puras, a questão não é agora de saber se isto ou aquilo acontece, mas sim que a razão por si mesma e independentemente de todos os fenômenos ordena o que deve acontecer; [...] porque este dever, como o dever em geral, anteriormente a toda a experiência, reside na ideia de uma razão que determina a vontade por motivos a priori ${ }^{10}$.

Para Kant, somente o uso da razão determina a moralidade, agindo de acordo com o dever, tendo a vontade de agir moralmente. Porém, a vontade humana é imperfeita e livre, podendo ocorrer desta querer algo contrário à razão. Visto que o homem, por sua natureza mista, é obrigado porque, por mais racional que ele seja, não se afasta da natureza sensível, tão somente a supera, sendo neste sentido obrigado a obedecer ao princípio moral. A vontade pois:

Não é outra coisa senão razão prática [...], isto é, a vontade é a faculdade de escolher só aquilo que a razão, independentemente da inclinação, reconhece como praticamente necessário, quer dizer como bom. [...] A representação de um princípio objetivo, enquanto obrigante para a vontade, chama-se um mandamento (da razão), e a fórmula do mandamento chama-se Imperativo ${ }^{11}$.

A vontade, em Hegel, ocorre de forma evolutiva, seguindo três formas: iniciando com uma vontade particular ou natural ${ }^{12}$ do indivíduo, ela é imediata. Nesta há os instintos e os desejos. A segunda forma da vontade é a vontade reflexiva, com a qual o indivíduo passa a escolher suas

${ }^{10}$ KANT, Immanuel. Fundamentação da Metafísica dos Costumes. Lisboa, Portugal: Edições 70, 2009, BA $27-$ 28.

${ }^{11}$ KANT, Immanuel. Fundamentação da Metafísica dos Costumes. Lisboa, Portugal: Edições 70, 2009, BA 3637.

${ }^{12}$ Essa denominação de vontade natural, vontade reflexiva e vontade livre é utilizada por Denis Rosenfield (ROSENFIELD, Denis. Política e Liberdade em Hegel. São Paulo: Editora Ática, 1995, p. 35-57).

\begin{tabular}{|c|c|l|l|c|c|}
\hline intuitio & $\begin{array}{c}\text { ISSN } \\
1983-4012\end{array}$ & Porto Alegre & Vol.7- $\mathrm{N}^{\mathrm{o} .2}$ & $\begin{array}{c}\text { Novembro } \\
2014\end{array}$ & p. 226-235 \\
\hline
\end{tabular}


inclinações e busca a satisfação desta. O terceiro nível é o da vontade livre, que está voltada ao universal, pois ela quer a si mesma. A vontade livre contém em si a racionalidade e a autonomia, ela é a ideia da liberdade, ou seja, a vontade livre alavanca a ideia de liberdade, para posteriormente ser concretizada, efetivada ${ }^{13}$.

Para que essa ideia da liberdade se concretize é necessário o desenvolvimento do "Sistema do Direito Hegeliano", partindo da conceituação de "pessoa do direito". Ser pessoa do direito significa ter a capacidade de possuir direitos e deveres para com a sociedade. Assim, os homens se tornam iguais, podendo se entender a dignidade humana consistindo no fato de reconhecer ${ }^{14}$ a razão em si mesma.

Seelman explica da seguinte forma, citando Hegel:

O homem não possui dignidade por meio daquilo que ele é como vontade imediata, mas apenas na medida em que conhece um ser ser-em-si um ser-para-si, algo substancial, e submete a esse ser a sua vontade natural e a adapta a ele. Apenas pelo suprassumir da indomabilidade natural e pelo reconhecimento de que um universal, um ser-em-si e um ser-para-si, seria verdade, ele possui uma dignidade, e só então a vida vale algo 15 .

Em resumo, é possível perceber a concepção hegeliana de dignidade, visto que o "reconhecimento recíproco é o fundamento da dignidade e, ao mesmo tempo, a consequência da opção por um estado juridicamente ordenado"16. O reconhecimento, sendo fundamento da dignidade, é também indispensável ao Estado, e de forma geral à Filosofia de Hegel, pois é somente com ele que podem ser obtidos os requisitos do desenvolvimento para atingir o Estado.

No entendimento de Hegel, a dignidade existe com o reconhecimento da razão. Ela é intrínseca apenas em parte, pois precisa ser desvelada. Tal desenvolvimento da razão faz parte disso: o indivíduo não se compreende como fim em si mesmo se não compreender a razão de si. $\mathrm{O}$ aperfeiçoamento da razão ocorre por meio do movimento dialético ${ }^{17}$, ao qual ela, a razão, sendo a "afirmação", se opõe a si mesma, constituindo a "negação", para posteriormente se unir a si novamente, sendo a negação da negação, completando assim o ciclo, resultando na razão desenvolvida, que reconhece a si como razão em si mesma.

\footnotetext{
${ }^{13}$ A "efetivação", em Hegel, consiste em conter algo na ideia e no espírito, ou seja, no caso da liberdade, ela é pensada e idealizada, para posteriormente ser realizada, se tornando assim realidade efetiva.

${ }_{14}$ Reconhecer e reconhecimento são conceitos complexos no pensamento hegeliano. Para obter o reconhecimento é preciso haver reciprocidade, ou seja, é preciso um reconhecimento mútuo, e este. Provém de um conflito. Entretanto, não existe conflito se as partes não se reconhecem minimamente. Sem reconhecimento, não é possível ocorrer relações sociais.

15 SEELMAN, Kurt. Pessoa e Dignidade da Pessoa Humana na Filosofia de HEGEL. In: SARLET, Ingo Wolfgang (Org.) Dimensões da dignidade: ensaios de filosofia do direito e direito constitucional. Porto Alegre: Livr. do Advogado, 2005, p. 51-52.

16 SEELMAN, Kurt. Pessoa e Dignidade da Pessoa Humana na Filosofia de HEGEL. In: SARLET, Ingo Wolfgang (Org.) Dimensões da dignidade: ensaios de filosofia do direito e direito constitucional. Porto Alegre: Livr. do Advogado, 2005, p. 59.

${ }^{17} \mathrm{O}$ movimento dialético é cíclico e não pára. Ele consiste em afirmação, negação, e negação da negação, surgindo uma nova afirmação, a qual contém em si superada e guardada as fases anteriores. Posteriormente a Hegel, com Popper, determinou-se de tese, antítese e síntese.
}

\begin{tabular}{|c|c|c|c|c|c|}
\hline intuitio & $\begin{array}{c}\text { ISSN } \\
1983-4012\end{array}$ & Porto Alegre & Vol.7- No.2 & $\begin{array}{c}\text { Novembro } \\
2014\end{array}$ & p. 226-235 \\
\hline
\end{tabular}


Não diferente de Kant, em Hegel o homem tem seu valor, ou dignidade com o pensamento, com a razão:

Pertence à cultura, ao pensar como consciência do singular na forma da universalidade, o fato de que eu seja apreendido enquanto pessoa universal, no que todos são idênticos. O homem vale assim, porque ele é homem, não porque ele é judeu, católico, protestante, alemão, italiano etc. essa consciência, pela qual o pensamento vale, é de uma importância infinita, - apenas é insuficiente quando se fixa, enquanto cosmopolitismo, num opor-se à vida concreta do Estado ${ }^{18}$.

Porém, a razão, para Hegel, tem o fator histórico que Kant aparentemente não considerou. A razão hegeliana é histórica, ela não está apenas na história, ela "é” a história, ela não está no tempo, ela "é" o tempo e proporciona sentido a este. Pois a transformação da razão e de seus conteúdos é obra racional da própria razão, e por isso ela não é algo relativo, passível de perder seu valor, suas verdades e sua universalidade.

Pode se entender então que, para Hegel, a dignidade é uma qualidade que precisa ser conquistada, ou seja, que o ser humano se torna digno quando começa a assumir sua condição de cidadão. Esta concepção afirma que a dignidade precisa de reconhecimento, que ela se afirma com a ideia de que cada um deve ser pessoa e respeitar os outros como pessoa. Sendo pessoa do direito, é garantida a dignidade, ou seja, o direito é garantia da dignidade, e se chega à autonomia com o desenvolvimento do Sistema.

Kant relaciona a autonomia com o "reino dos fins", que consiste numa sociedade composta de seres racionais que seguem as mesmas leis; uma comunidade na qual se teria, entre os seres racionais, um tratamento de cada um, e inclusive a si mesmo, como "um fim em si mesmo", e também possuindo as leis como sendo escolhidas e impostas por cada um a si mesmo, afirmando sua autonomia. Segundo Kant "A autonomia é o fundamento da dignidade da natureza humana e de toda a natureza racional" 19 . Com isso, autonomia é a capacidade de agir por meio de máximas racionais, podendo ser considerada um dos elementos que constituem a maioridade do ser humano. Ao afirmar a autonomia se afirma também a dignidade do ser humano, ou como expõe Weber:

Kant pressupõe a personalidade moral (qualidades morais) como condição para ser membro de um reino dos fins (uma comunidade moral). É essa capacidade de ter boa vontade ou caráter moralmente bom que implica dignidade. Considerar-se a si e aos outros como fins em si mesmos é reconhecer sua dignidade e reconhecê-la é reconhecer sua autonomia ${ }^{20}$

O ser humano, tendo capacidade de ter boa vontade, é merecedor do respeito à sua dignidade, e no reino dos fins, ao se reconhecer os outros como seres dignos, como fim em si mesmo, e não como objeto ou meio, se reconhece também sua autonomia. O ser humano legisla para si e para os outros,

${ }^{18}$ HEGEL, G. W. F. Linhas fundamentais da filosofia do direito, ou, Direito natural e ciência do estado em compêndio. São Leopoldo: Loyola, 2010, § 209, p. 203. Grifos do autor.

${ }^{19}$ KANT, Immanuel. Fundamentação da Metafísica dos Costumes. Lisboa, Portugal: Edições 70, 2009 , BA 79.

${ }^{20}$ WEBER, Thadeu. Ética e Filosofia do Direito: Autonomia e dignidade da pessoa humana. Petrópolis, RJ: Vozes, 2013, p. 32.

\begin{tabular}{|c|c|l|l|c|c|}
\hline intuitio & $\begin{array}{c}\text { ISSN } \\
1983-4012\end{array}$ & Porto Alegre & Vol.7- $\mathrm{N}^{\mathrm{o} .2}$ & $\begin{array}{c}\text { Novembro } \\
2014\end{array}$ & p. 226-235 \\
\hline
\end{tabular}


isso é autonomia. Sendo assim, pode-se dizer que a moralidade kantiana é a relação entre as ações e a autonomia da vontade, pois Santos afirma:

é com base neste princípio - o princípio da autonomia - bem como nos conceitos correlatos, isto é, liberdade da vontade ou vontade livre (vontade legisladora), reino dos fins, dignidade, humanidade, que toda a filosofia moral kantiana será concebida e desenvolvida em suas diferentes etapas e desenvolvimentos. Temos, portanto, neste conceito o pilar de sustentação da fundamentação da filosofia moral kantiana $^{21}$.

O princípio da autonomia, sendo o pilar de sustentação da fundamentação da filosofia moral kantiana, o é juntamente com a dignidade e os demais conceitos, pois são correlatos. O princípio da autonomia consiste em escolher as máximas que podem se tornar leis universais. Entretanto, o ser humano é autônomo na medida em que obedece às leis universais provindas dele mesmo, ou seja "Somos autônomos quando obedecemos à lei da qual fomos autores",22, afirma Weber.

A relação que existe entre o ser humano e o Estado, em Hegel, começa a se desenvolver a partir do momento em que este indivíduo se reconhece como um ser que possui uma vontade livre, que é o princípio a ser realizado pelo Direito. A realização da liberdade vem a ser, conforme o desenvolvimento desse Sistema, o objetivo final do Estado.

Ao tratar do Direito Abstrato, Hegel defende que: "pelo mesmo fundamento dessa sua abstração, a necessidade desse direito delimita-se ao aspecto negativo de não lesar a personalidade e o que deriva dela" ${ }^{\prime 2}$. Em outros termos, o direito abstrato tem a função de organizar a relação entre as pessoas de tal forma que, para que não ocorra de uma pessoa lesar outra, podendo asseverar que o direito abstrato é a forma inicial, que contém a ideia da liberdade também de forma inicial. Nesse Direito se busca preservar a dignidade de cada pessoa, sendo o Estado a etapa final, em que a liberdade é concretizada. Enquanto o Direito Abstrato trata de pessoas imediatas, o Estado trata "de instituições e estamentos, onde as pessoas, com seus interesses particulares, estão como mediadas e, desse modo, superadas e conservadas" ${ }^{24}$.

No Direito Abstrato, a maneira de se tornar pessoa é com a posse de alguma propriedade, efetivando assim sua capacidade legal, afirmando sua personalidade. As pessoas sendo iguais, merecem respeito, de acordo com Weber: "Qualquer pessoa é "sujeito" e tem, desse modo, o direito de não ser tratada como coisa" ${ }^{25}$. A propriedade afirma a vontade autônoma e o indivíduo como pessoa, para, a parti, do contrato, que é posterior à propriedade e responsável pela troca desta, o indivíduo

${ }^{21}$ SANTOS, Robinson dos. Liberdade e coerção: a autonomia moral é ensinável? Studia Kantiana. Pelotas: UFPel. Número 11, p. 201-216. Dez. 2011, p. 206.

${ }^{22}$ WEBER, Thadeu. Ética e Filosofia do Direito: Autonomia e dignidade da pessoa humana. Petrópolis, RJ: Vozes, 2013, p. 24.

${ }^{23}$ HEGEL, G. W. F. Linhas fundamentais da filosofia do direito, ou, Direito natural e ciência do estado em compêndio. São Leopoldo: Loyola, 2010, §38, p. 81. Grifos do autor.

${ }^{24}$ WEBER, Thadeu. Ética e Filosofia do Direito: Autonomia e dignidade da pessoa humana. Petrópolis, RJ: Vozes, 2013, p. 96.

${ }^{25}$ WEBER, Thadeu. Ética e Filosofia do Direito: Autonomia e dignidade da pessoa humana. Petrópolis, RJ: Vozes, 2013, p. 91.

\begin{tabular}{|c|c|l|l|c|c|}
\hline intuitio & $\begin{array}{c}\text { ISSN } \\
1983-4012\end{array}$ & Porto Alegre & Vol.7- $\mathrm{N}^{\mathrm{o} .2}$ & $\begin{array}{c}\text { Novembro } \\
2014\end{array}$ & p. 226-235 \\
\hline
\end{tabular}


começar a possuir o reconhecimento do outro como pessoa, com todas suas qualidades: autônomo e digno. Sendo o reconhecimento indispensável para o exercício da liberdade.

Continuando o processo de desenvolvimento desse Sistema, a Moralidade se preocupa com os princípios da pessoa ao agir, pessoa que, a partir desse momento, se torna sujeito do direito. Tendo a subjetividade da liberdade em evidência, se investiga a autodeterminação da vontade, os propósitos e a intenção do sujeito, obtendo assim o direito da autonomia. Na Moralidade, então, está contida a autonomia da vontade com sentido moral e responsabilidade, ou seja, nela está presente o saber e o querer agir com responsabilidade, mantendo ainda sua subjetividade da vontade. A vontade subjetiva reconhece só o que é seu, o que esta sabe e o que ela quer fazer.

$\mathrm{Na}$ Eticidade, o sujeito é considerado membro da comunidade ética, e com esta Hegel supera a moralidade, sendo no Estado que se têm definidos e garantidos os deveres e os direitos e é, portanto, nele que a liberdade se realiza. Weber nesta temática sugere a seguinte tradução do $§ 260$ da obra Filosofia do Direito de Hegel:

\begin{abstract}
A liberdade concreta consiste em que a individualidade pessoal e seus interesses particulares tenham seu total desenvolvimento e o reconhecimento de seu direito (no sistema da família e da sociedade civil), ao mesmo tempo que se convertem, por si mesmos, em interesse geral, que reconhecem com seu saber e sua vontade como seu próprio espírito substancial e tomam como fim último de sua atividade. Desse modo o universal não se cumpre, nem tem validade sem o interesse, o saber e o querer particular, nem o indivíduo vive meramente para estes últimos como uma pessoa privada, sem querer ao mesmo tempo o universal e ter uma atividade consciente dessa finalidade ${ }^{26}$.
\end{abstract}

Explicita-se, assim, que a efetivação da liberdade ocorre com o desenvolvimento desta, podendo-se, desta forma deduzir que assim como a liberdade, a autonomia e a dignidade no âmbito da eticidade são garantidas pelo Estado, devido ao desenvolvimento de superação (Aufhebung) ocorrido. Entretanto, o Direito não trata de questões subjetivas da vontade, ele apenas ordena as leis e estas devem ser cumpridas. Na Moralidade o subjetivo está presente, tratando do direito da vontade de saber e reconhecer o que existe em sua vontade. E na Eticidade existe a superação da subjetividade e o dever-ser como resultado disso.

Para Weber:

O problema central levantado por Hegel, no que se refere à Filosofia prática de Kant, é que este permanece no plano da subjetividade e não passa ao nível das determinações objetivas da vontade livre. Considera a pureza da intenção como critério fundamental da moralidade e não leva em conta os resultados e consequências dos atos humanos. Por conseguinte, não pensa uma ética da responsabilidade $^{27}$.

\footnotetext{
${ }^{26}$ WEBER, Thadeu. Ética e Filosofia Política: Hegel e o formalismo kantiano. Porto Alegre: EDIPUCRS, 1999, p. 133-134.

${ }^{27}$ WEBER, Thadeu. Ética e Filosofia Política: Hegel e o formalismo kantiano. Porto Alegre: EDIPUCRS, 1999, p. 97.

\begin{tabular}{|c|c|c|c|c|c|}
\hline intuitio & $\begin{array}{c}\text { ISSN } \\
1983-4012\end{array}$ & Porto Alegre & Vol.7- No.2 & $\begin{array}{c}\text { Novembro } \\
2014\end{array}$ & p. 226-235 \\
\hline
\end{tabular}
}


Kant não distingue a moralidade da eticidade, enquanto que Hegel, em sua ética da responsabilidade, sustenta que é necessário a objetivação da moralidade subjetiva, a qual ocorre na eticidade, momento em que a liberdade subjetiva torna-se universalizada. Entretanto, é na eticidade que as instituições sociais da família, sociedade civil e Estado tem espaço, ocorrendo nestas a relação entre os indivíduos e as suas vontades, assim como a relação entre os deveres e os direitos do cidadão. $\mathrm{Na}$ qual o reconhecimento da dignidade deve ser recíproco.

O Estado, nesse sistema apresentado por Hegel, tem a função de mediar essas relações entre as instituições, para manter uma harmonia. Portanto, nessas existem as relações da dignidade e da autonomia dos indivíduos considerados no Estado como membros de uma comunidade. A dignidade é então, após o desenvolvimento e a superação do Sistema do Direito hegeliano, garantida pelo direito, assim como a autonomia, pois existe reconhecimento mútuo entre os cidadãos, os quais se reconhecem e se respeitam por serem cidadãos do Estado, mantendo a dignidade humana.

\section{Referências}

ABBAGNANO, Nicola. Dicionário de Filosofia. 5 ed. São Paulo: Martins Fontes, 2007.

AQUINO, Santo Tomás de. Suma de Teología. 4.ed. Espanã: Biblioteca de autores cristianos, 2001.

CÍCERO. Dos Deveres (De Officiis). Lisboa, Portugal: Edições 70.

HEGEL, G. W. F. Fenomenologia do Espírito. Trad. Paulo Meneses. 2 ed. Petrópolis: Vozes, 1992.

Linhas fundamentais da filosofia do direito, ou, Direito natural e ciência do estado em compêndio.

São Leopoldo: Loyola, 2010.

KANT, Immanuel. Fundamentação da Metafísica dos Costumes. Lisboa, Portugal: Edições 70, 2009. . A Metafísica dos Costumes. Trad. José Lamego. 2.ed. Lisboa: Fundação Calouste Gulbenkian, 2011.

PUFENDORF, Samuel von. Of the law of nature and nations. 1. ed. Oxford: L. Lichfield, 1710. Disponível em: http://books.google.com.br/books

ROSENFIELD, Denis. Hegel. Rio de Janeiro: Jorge Zahar Editor, 2002. .Politica e Liberdade em Hegel. São Paulo: Editora Ática, 1995.

SANTOS, Robinson dos. Liberdade e coerção: a autonomia moral é ensinável? Studia Kantiana. Pelotas: UFPel. Número 11, p. 201-216. Dez. 2011.

SEELMAN, Kurt. Pessoa e Dignidade da Pessoa Humana na Filosofia de HEGEL. In: SARLET, Ingo Wolfgang (Org.) Dimensões da dignidade: ensaios de filosofia do direito e direito constitucional. Porto Alegre: Livr. do Advogado, 2005.

SENSEN, Oliver. Kant on human dignity. Gottingen: Gruyter, 2011.

WEBER, Thadeu. Ética e Filosofia Política: Hegel e o formalismo kantiano. Porto Alegre: EDIPUCRS, 1999. . Ética e Filosofia do Direito: Autonomia e dignidade da pessoa humana. Petrópolis, RJ: Vozes, 2013.

Recebido em: 29/09/2014

Aprovado para publicação em 01/10/2014

\begin{tabular}{|c|c|l|l|c|c|}
\hline intuitio & $\begin{array}{c}\text { ISSN } \\
1983-4012\end{array}$ & Porto Alegre & Vol.7- $\mathrm{N}^{\mathrm{o} .2}$ & $\begin{array}{c}\text { Novembro } \\
2014\end{array}$ & p. 226-235 \\
\hline
\end{tabular}

